\title{
ROBOTIC TECHNOLOGY CAN BE A USEFUL TOOL IN TKR IN A POST-CABG PATIENT: A CASE REPORT AND LITERATURE REVIEW
}

\section{Orthopaedics}

\section{Dr. Varun $\mathbf{O}$.} Agrawal*

\section{Dr. Satish P. Kale}

M.B.B.S., D. Ortho, FJRS Consultant Orthopaedic Surgeon, Joint replacement and Trauma Department, Lokmanya Hospital, Pune, Maharashtra, India. *Corresponding Author

M.B.B.S., D. Ortho, DNB Orthopaedics, Consultant Orthopaedic Surgeon, Joint replacement and Trauma Department, Lokmanya Hospital, Pune, Maharashtra, India.

M.B.B.S., M.S.(Ortho), DNB (Ortho), M. Ch (Ortho), Head of the Department, Joint replacement and Trauma, Lokmanya Hospital, Pune, Maharashtra, India.

\section{Vaidya}

\section{ABSTRACT}

Background: - Total knee replacement (TKR) is a major surgery associated with complications like pulmonary embolism, myocardial infarction, deep vein thrombosis and death. Associated risk factors like old age, male gender, pre-existing cardiac disease increase the risk of these postoperative complications. Use of robotic technology leads to reduced blood loss, decreased risk of pulmonary embolism and related complications. In our study, we evaluated the use of this technology in a patient undergoing total knee replacement, post coronary artery bypass grafting surgery. Case Presentation: - An 85y old male patient, known case of hypertension, diabetes mellitus, ischaemic heart disease, who had undergone coronary artery bypass grafting (12 years back), presented with severe osteoarthritis in left knee, and was operated for total knee replacement surgery using robotic technology. The procedure was uneventful with satisfactory recovery of the patient. Use of robotic technology, along with good perioperative planning and its execution can help achieve successful outcomes in patients with cardiopulmonary risk factors.

\section{KEYWORDS}

Total knee replacement, TKR, knee arthroplasty, cardiopulmonary risk factors, robotic-assisted knee replacement.

\section{INTRODUCTION:-}

Total knee replacement (TKR) has traditionally been seen as a highly demanding surgery associated with major blood loss in patients belonging to older age group often having comorbidities. Older age group, male gender and pre-existing cardiac disease increase the risk of complications after TKR surgery. ${ }^{1-5}$ Clinically significant complications like myocardial infarction (MI), pulmonary embolism (PE), deep vein thrombosis (DVT) and death are known to occur following total knee arthroplasty (TKA) with an overall frequency of $2.2 \%$. ${ }^{6}$ Use of robotic technology for TKR surgery averts the risk of embolism and other cardiopulmonary complications along with improving the accuracy and precision of the surgery. ${ }^{7-14}$ It also leads to reduced pain and decreases the patient stay in the hospital. ${ }^{14,15}$ The patient in our case was an 85 years old male who was a known case of diabetes mellitus (DM), hypertension (HTN), ischaemic heart disease (IHD) and had previously undergone coronary artery bypass grafting $(\mathrm{CABG})$ and presented with left knee severe degenerative arthritis. We planned to do total knee replacement surgery using the robotic technology considering the beneficial effects over the conventional method. Use of this technology coupled with comprehensive perioperative planning and execution led to a successful outcome in a high-risk case like post-CABG

\section{CASE PRESENTATION: -}

\subsection{Clinical History: -}

An 85-year old thin male patient presented with the complaint of pain in the left knee for the past 4 years. He had pain while getting up from sitting position and difficulty in climbing stairs. He was a known case of DM, HTN and IHD. He had undergone CABG surgery 12 years back. The patient belonged to American Society of Anaesthesiologists (ASA) class 3.

\subsection{Physical Examination:-}

During preoperative examination, patient had a pulse rate of 80 per minute and blood pressure was $140 / 70 \mathrm{mmHg}$. There was no angina or dyspnoea on exertion. Patient came with a waddling gait. Medial and lateral joint line tenderness was present with a positive crepitus. 10 degrees of fixed flexion deformity (FFD) was present with a further flexion up to 110 degrees. There was a mild varus deformity with a mediolaterally lax joint. Patellofemoral tenderness was present.

Patient was on (Telmisartan 40mg + Amlodipine 5mg), Atorvastatin $20 \mathrm{mg}$, Aspirin $75 \mathrm{mg}$ and Glyceryl trinitrate $2.6 \mathrm{mg}$ and oral hypoglycaemic drugs.

\subsection{Investigations: -}

Electrocardiogram (ECG) showed incomplete right bundle branch block (RBBB) and T-inversion in chest leads. 2D echo was nearly normal with a Grade 1 diastolic dysfunction and $60 \%$ left ventricular ejection fraction (LVEF). Dobutamine stress test was positive for inducible ischemia at peak dose $(72 \mathrm{mg} @ 20 \mathrm{mcg} / \mathrm{kg} / \mathrm{hr})$. During the testing, patient had angina at peak dose with ST-T changes.

Xray anteroposterior (standing) (Image 1A), lateral (Image 1B) and skyline (Image 1C) views showed severe degenerative changes in all the 3 compartments with bony deformity and multiple osteophytes. Valgus stress view (Image 1D) showed the opening of medial joint space showing the lax nature of the joint.

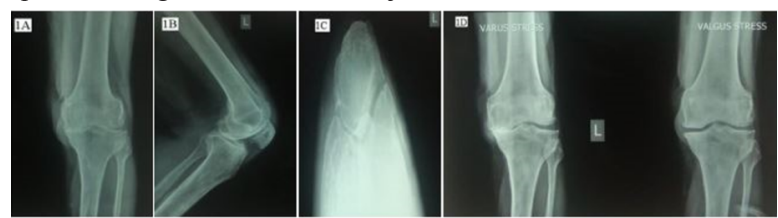

Image 1: Pre-op X-rays. A. AP (standing) B. lateral C. Skyline D. Varus-valgus stress views. These $\mathrm{X}$-rays show the degenerative osteoarthritic changes in the left knee joint.

\subsection{Management: -}

Patient had tried for all sorts of conservative management but did not find relief. Hence, he was planned for total knee replacement surgery using robotic technology (Navio PFS by Blue Belt Technologies, Plymouth, MN). Aspirin $75 \mathrm{mg}$ was stopped 5 days prior to the surgery.

Regional anaesthesia (spinal + epidural) was chosen. Throughout the surgery, the blood pressure maintained was $\leq 140 / 90 \mathrm{mmHg}$. The surgery was done under tourniquet pressure of $310 \mathrm{mmHg}$. Medial parapatellar approach was used. Using the robotic technology, complete deformity could be corrected by measured bony resection and minimal soft tissue release. The implant used was fixed-bearing cruciate-retaining prosthesis. Image $\mathbf{2}$ shows the intra-op screen on robotic system after the fixation of final implants that explains how precisely the planned alignment could be achieved using the robotic technology and measured resection technique. The tourniquet was deflated after the cement was completely set. Haemostasis was achieved by coagulating the bleeders. The total tourniquet time was 30 mins. The tourniquet was released in a gradual controlled manner along with a dose of injection Mephentermine. Intra-articular vacuum suction drain was kept postoperatively for $24 \mathrm{hrs}$. Total amount of blood collected in the drain was $80 \mathrm{ml} .3$ doses of $500 \mathrm{mg}$ tranexamic 
acid were given, $1^{\text {st }}$ being intra-op and 2 doses at $12 \mathrm{hrly}$ intervals thereafter. Postoperatively patient was started on Inj. Enoxaparin $0.4 \mathrm{ml} \mathrm{s} / \mathrm{c} \mathrm{OD}$. Post-op patient was kept in intensive care unit (ICU) for monitoring for 24 hours. O2 support was given at 2 litres per minute, using mask, for 24 hrs. Postoperative X-rays (Image 3) were taken on the same day of the surgery.

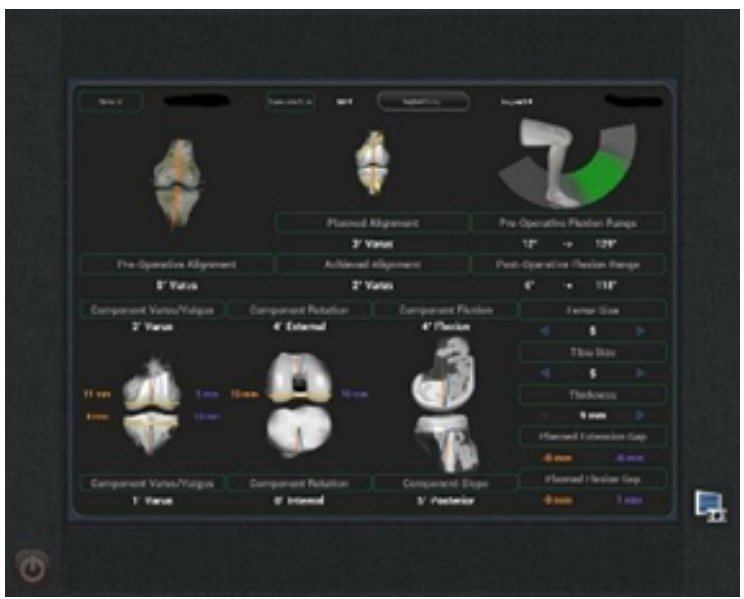

Image 2: Intra-op findings on the screen of the robotic system after the fixation of final implants during total knee arthroplasty surgery. These findings show how precisely robotic technology helps in achieving kinematic alignment of the knee that can be confirmed with the objective readings.

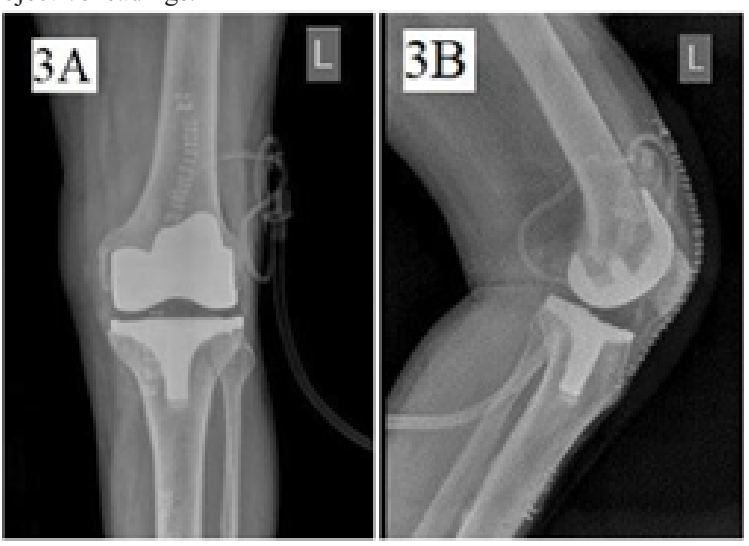

Image 3: Post-op X-rays: A. AP view B. Lateral view. These X-rays show the accurate positioning of the implants and alignment of the knee obtained after total knee arthroplasty using robotic system.

Postoperative physiotherapy was started from the day of surgery itself. The physiotherapy protocol followed was as below: -

\begin{tabular}{|l|l|}
\hline $\begin{array}{l}\text { 1. Post-Operative Day } \\
\text { (POD)-0 }\end{array}$ & $\begin{array}{l}\text { Static and dynamic quadriceps, } \\
\text { hamstrings and Vastus Medialis } \\
\text { Oblique (VMO) exercises }\end{array}$ \\
\hline 2. POD-2 & $\begin{array}{l}\text { Active flexion: 30-40 degrees; } \\
\text { Straight Leg Raising (SLR): 20-30 } \\
\text { degrees (active assisted); } \\
\text { Bedside sitting; } \\
\text { 20 steps with walker }\end{array}$ \\
\hline $\begin{array}{l}\text { 3. POD-3 (Day of } \\
\text { Discharge) }\end{array}$ & $\begin{array}{l}\text { Active flexion: 70-80 degrees; } \\
\text { Active SLR: 50-60 degrees; } \\
\text { 60 steps with walker; } \\
\text { Staircase: 8 steps up and down }\end{array}$ \\
\hline $\begin{array}{l}\text { 4.2 weeks (Day of stitch } \\
\text { removal) }\end{array}$ & $\begin{array}{l}\text { Active flexion: 90-100 degrees; } \\
\text { Active SLR: free, complete; } \\
\text { Came to out-patient department (OPD) } \\
\text { walking without walker }\end{array}$ \\
\hline 5.2 months & $\begin{array}{l}\text { Active flexion: 120-130 degrees; } \\
\text { Walking daily 3-4 kms }\end{array}$ \\
\hline 6.6 months & $\begin{array}{l}\text { Active flexion: 120-130 degrees; } \\
\text { Riding two-wheeler comfortably }\end{array}$ \\
\hline
\end{tabular}

The range of knee motion, SLR, walking ability and daily routine activities of the patient showed a rapid improvement. This led to decreased postoperative morbidity and improved patient satisfaction.

\section{DISCUSSION:-}

Total knee replacement has traditionally been seen as a highly demanding surgery associated with major blood loss in patients belonging to older age group often having comorbidities. Previous studies have focussed on the factors which lead to an increased risk of complications after TKR surgery. Elsiwy et al. ${ }^{1}$ stated that there is an increased risk of cardiac complications if TKR is done in a patient belonging to higher age group and with a history of cardiac disease. J. Robinson et $\mathrm{al}^{2}{ }^{2}$ and Menendez et al. ${ }^{3}$ found an association between male gender and increased risk of MI following TKR. B. R. Waterman et al. ${ }^{4}$, Belmont et al. ${ }^{5}$ and Menendez et al. ${ }^{3}$ showed an increased risk of cardiac complications in patients $>80$ years age. Belmont et al. ${ }^{5}$ and Menendez et al. ${ }^{3}$ showed an increased risk in patients with DM. Belmont et al. ${ }^{5}$ and B. R. Waterman et $\mathrm{al}^{4}{ }^{4}$ found HTN to increase the risk of complications in patients, post-surgery. Our patient was an 85 year old male having DM, HTN and who had undergone CABG surgery 12 years back.

As per the criteria explained by Hedge et al. ${ }^{16}$ for the assessment of the perioperative cardiovascular risk, our patient belonged to intermediate cardiac risk category $(<5 \%)$ of the clinical predictors and elevated risk category $(>1 \%)$ as per the ACC/AHA guidelines for non-cardiac surgical procedures.

Regional anaesthesia (graded epidural + low dose spinal) was given due to its advantages over general anaesthesia. ${ }^{17}$ Some disadvantage of regional anaesthesia may be mentioned like hypotension, due to sympathetic blockade, that may precipitate ischaemia. Also, larger doses can lead to myocardial toxicity and thus, ischemia. ${ }^{17}$ Our patient was on Angiotensin Receptor Blockers (ARBs), Calcium Channel Blockers (CCBs) and Nitrates. These drugs are found to be beneficial perioperatively as per Tej K. Kaul et al. ${ }^{17}$ However, our patient had preoperative BP of $140 / 70 \mathrm{mmHg}$. Therefore, we decided to give none of these drugs as intervention is not advised perioperatively for improving the outcome (except for beta blockers or alpha, agonists). As per the American Society of Regional Anaesthesia and Pain Medicine (ASRA) guidelines ${ }^{18}$, aspirin does not increase the risk of spinal hematoma during spinal or epidural anaesthesia, hence, need not be stopped. However, TKR being a major surgery, it is advised to stop aspirin 5-10 days before the procedure. ${ }^{19-23}$ Our patient was taking aspirin $75 \mathrm{mg}$. We decided to stop aspirin 5 days prior to surgery to avoid increased blood loss during the surgery.

In his study, Hedge et al. ${ }^{16}$ stated that continuous intra-op monitoring using pulse- oximeter, capnography, urine output, temperature, noninvasive blood pressure and electrocardiography is essential in a patient with ischemic heart disease. All these factors were taken care of during the surgery.

We planned to use robotic (Navio) surgical system for TKR in our patient. This technique does not require the use of intramedullary reaming and femoral alignment rod for planning of the distal femoral cut. This averts the risk of embolism and other cardiopulmonary complications as mentioned by Christie et al., ${ }^{24}$ Coles et al., Schemitsch et al., ${ }^{7}$ Muller et al. ${ }^{8}$ and Husebye et al. ${ }^{9}$ in their respective works. This has also found to reduce the postoperative drainage, as stated by Song et al ${ }^{10}$ in his study. Bellemans et al., ${ }^{11}$ Lang et al. ${ }^{12}$ and J. A. Browne et al. ${ }^{13}$ have explained how robotic technology helps in achieving better component positioning and better kinematic alignment of the joint with a decreased rate of complications. Work by Bellemans et al., ${ }^{11}$ Lang et al. ${ }^{12}$ and Clark et al. ${ }^{14}$ showed the increase in precision and accuracy of the surgery with this technique. Further, as per Clark et al., ${ }^{14}$ robotic devices decrease the length of stay in the hospital. As stated by Kayani et al., ${ }^{15}$ the postoperative pain is less with this technique as compared to the conventional method which, in turn, leads to faster recovery and shorter hospital stay. The reason for reduced pain with this technique found was improved preservation of soft-tissue envelope and reduced iatrogenic trauma.

We aimed to achieve minimum perioperative blood loss to avert the risk of haemodynamic complications which our patient was already at risk of. The total amount of blood loss in our case was $516 \mathrm{~m}$ calculated by using the $\mathrm{Hb}$ balance method $\mathrm{d}^{26-30}$ for estimation of blood loss. This value is much lesser than the allowable blood loss ${ }^{31}(1246$ 
$\mathrm{ml}$ ) for our case. Robotic technique reduced the postoperative drainage and, thus, reduced the perioperative blood loss as stated by Song et al. ${ }^{10}$ and Conteduca et al. ${ }^{32}$ In addition to this, use of tourniquet, ${ }^{33}$ diathermy cautery, ${ }^{34}$ antifibrinolytic agents ${ }^{35}$ and a minimally invasive surgery ${ }^{36,37}$ also helped in reducing blood loss. A lesser tourniquet time (30 mins) due to the faster surgery, assisted by a well-trained and experienced personnel, added to the goal. The gradual controlled release of the tourniquet accompanied by a dose of Inj. Mephentermine helped preventing any episode of hypotension and subsequent failure associated with tourniquet release. ${ }^{38}$

As stated by Mantilla et al., ${ }^{6}$ clinically significant complications like MI, PE, DVT and death are known to occur following TKR with an overall frequency of $2.2 \%$. Tej K. Kaul et al. ${ }^{17}$ mentioned that most cardiac events occur within first $48 \mathrm{hrs}$ post-surgery. This period was uneventful in our case. Delayed complications are known to occur within first 30 days due to secondary stress factors. No such complications were noted in our patient.

Thus, the use of robotic technology along with appropriate perioperative evaluation and planning of the case led to successful outcome for the patient and the surgeon both.

\section{CONCLUSION:-}

A good preoperative evaluation, proper surgical planning and execution along with the use of modern technology in the form of robotic-assisted knee replacement system helped us achieving successful outcome in a high-risk case like 85 years old male with DM, HTN, IHD and post-CABG.

\section{DECLARATION:-}

5.1 Informed Consent: - The written informed consent of the patient was taken for publication.

5.2 Conflict of interest: - The authors declare that they have no conflicts of interest.

5.3 Acknowledgement: - We would like to thank the patient who participated in our study. We would also like to thank the staff of hospital who contributed to our study.

\section{REFERENCES}

1. Elsiwy, Y., Jovanovic, I., Doma, K. et al. Risk factors associated with cardiac complication after total joint arthroplasty of the hip and knee: a systematic review. J Orthop Surg Res 14, 15 (2019) doi:10.1186/s13018-018-1058-9.

2. Robinson J, Shin JI, Dowdell JE, Moucha CS, Chen DD. Impact of gender on 30-day complications after primary total joint arthroplasty. J Arthroplasty. 2017;32(8):2370-2374.

3. Menendez ME, Memtsoudis SG, Opperer M, et al. A nationwide analysis of risk factors for in-hospital myocardial infarction after total joint arthroplasty. Int Orthop 2015; for in-hosp
39:777-86.

4. Waterman B R, Belmont P J, Jr, Bader J O, Schoenfeld A J. The Total Joint Arthroplasty Cardiac Risk Index for Predicting Perioperative Myocardial Infarction and Cardiac Arrest After Primary Total Knee and Hip Arthroplasty. J Arthroplasty. 2016;31(06):1170-1174

5. Belmont PJ, Goodman GP, Kusnezov NA, Magee C, Bader JO, Waterman BR, et al. Postoperative myocardial infarction and cardiac arrest following primary total knee and hip arthroplasty: rates, risk factors, and time of occurrence. J Bone Joint Surg Am. 2014;96(24):2025-2031. doi: 10.2106/JBJS.N.00153.

6. Mantilla CB, Horlocker TT, Schroeder DR, et al. Frequency of myocardial infarction, pulmonary embolism, deep venous thrombosis, and death following primary hip or knee pulmonary embolism, deep venous thrombosis, and death following primary hip or knee Schemitsch EH, Turchin DC, Anderson GI, et al. Pulmonary and systemic fat Schemitsch EH, Turchin DC, Anderson GI, et al. Pulmonary and systemic fat
embolization after medullary canal pressurization: a hemodynamic and histologic investigation in the dog. J Trauma. 1998; 45:738-742

8. Muller C, Rahn BA, Pfister U, et al. The incidence, pathogenesis, diagnosis, and treatment of fat embolism. Orthop Rev. 1994; 23:107-117.

9. Elisabeth Ellingsen Husebye, Torstein Lyberg, Helge Opdahl, Helene Laurvik, Olav Roise. Cardiopulmonary response to reamed intramedullary nailing of the femur comparing traditional reaming with a one-step reamer-irrigator-aspirator reaming system: an experimental study in pigs. J Trauma. 2010 Oct; 69(4): E6-14. doi: system: an experimental study

10. Song EK, Seon JK, Yim JH, et al. Robotic-assisted TKA reduces postoperative alignment outliers and improves gap balance compared to conventional TKA. Clin Orthop Relat Res 2013; 471:118-26.

11. J. Bellemans, H. Vandenneucker, and J. Vanlauwe, "Robot assisted total knee arthroplasty," Clinical Orthopaedics and Related Research. 2007; no.464, pp.111-116.

12. Lang JE, Mannava S, Floyd AJ, Goddard MS, Smith BP, Mofidi A, et al. Robotic systems in orthopaedic surgery. J Bone Joint Surg Br 2011; 93:1296-1299. doi: 10.1302/0301$620 \times .93 \mathrm{~B} 10.27418$

13. Browne JA, Cook C, Hofmann AA, Bolognesi MP. Postoperative morbidity and mortality following knee replacement with computer navigation. Knee. 2010; 17(2):152-156. [PubMed: 19758806]

14. Clark TC, Schmidt FH. Robot-Assisted Navigation versus Computer-Assisted Navigation in Primary Total Knee Arthroplasty: Efficiency and Accuracy. ISRN Orthop. 2013 Jun 24; 2013:794827. doi: 10.1155/2013/794827. PMID: 24967115; PMCID: PMC4045350.

15. Kayani B, Konan S, Tahmassebi J, Pietrzak JRT, Haddad FS. Robotic-arm assisted total knee arthroplasty is associated with improved early functional recovery and reduced
Bone Joint J. 100(7), 930-937(2018)

6. Hedge J, Balajibabu PR, Sivaraman T. The patient with ischaemic heart disease undergoing non cardiac surgery. Indian J Anaesth, (9):705-711. MED: 28970628

17. Kaul TK, Tayal G. Anaesthetic considerations in cardiac patients undergoing non cardiac surgery. Indian J Anaesth 2007; 51:280

18. Teresa HT, Erik V, Sandra KL, Weibke G, Lisa LR, Honorio BT. Regional Anesthesia in the Patient Receiving Antithrombotic or Thrombolytic Therapy: American Society of Regional Anesthesia and Pain Medicine Evidence-Based Guidelines (4th edition). Regional Anesthesia and Pain Medicine. April 2018 - Volume 43 - Issue 3 - p 263-309. doi: 10.1097/AAP.0000000000000763.

19. Kristensen SD, Knuuti J, Saraste A, et al.: 2014 ESC/ESA Guidelines on noncardiac surgery: cardiovascular assessment and management: The Joint Task Force on noncardia: carery: Cardics (ESC) and the Europess Society of Anget Cardiology (ESC) and the European Society of Anaesthesiology (ESA). Eur Heart J
2014;35:2383-431.

20. Douketis JD, Spyropoulos AC, Spencer FA, et al.: Perioperative management of antithrombotic therapy: Antithrombotic Therapy and Prevention of Thrombosis, 9th ed: American College of Chest Physicians Evidence-Based Clinical Practice Guidelines. Chest 2012; 141: e326S-50S

21. Koenig-Oberhuber V, Filipovic M: New antiplatelet drugs and new oral anti coagulants. Br JAnaesth 2016; 117 Suppl 2: ii74-ii84

22. Plümer L, Seiffert M, Punke MA, Kersten JF, Blankenberg S, Zöllner C, Petzoldt M. Aspirin Before Elective Surgery-Stop or Continue? Dtsch Arztebl Int. 2017 Ju 10;114(27-28):473-480. doi: 10.3238/arztebl.2017.0473. PMID: 28764836; PMCID: PMC5545631.

23. Clinical Excellence Commission, 2018, Guidelines on Perioperative Management of Anticoagulant and Antiplatelet Agents Sydney: Clinical Excellence Commission.

24. Christie J, Robinson CM, Pell AC, et al. Trans cardiac echocardiography during invasive intramedullary procedures. J Bone Joint Surg Br. 1995;77: 450-455.

25. Coles RE, Clements FM, Lardenoye JW, et al. Transesophageal echocardiography in quantification of emboli during femoral nailing: reamed versus unreamed techniques. J South Orthop Assoc. 2000;9: 98-104.

26. Nadler SB, Hidalgo JH, Bloch T. Prediction of blood volume in normal human adults Surgery $1962 ; 51: 224-32$

27. Good L, Peterson E, Lisander B. Tranexamic acid decreases external blood loss but not hidden blood loss in total knee replacement. Br J Anaesth 2003; 90:596-9.

28. Lisander B, Ivarsson I, Jacobsson SA. Intraoperative autotransfusion is associated with modest reduction of allogeneic transfusion in prosthetic hip surgery. Acta Anaesthesio Scand 1998; 42:707-12.

29. Foss NB, Kehlet H. Hidden blood loss after surgery for hip fracture. J Bone Joint Surg B 2006; 88:1053-9.

30. Gao FQ, Li ZJ, Zhang K, Sun W, Zhang H. Four Methods for Calculating Blood-los after Total Knee Arthroplasty. Chin Med J (Engl). 2015 Nov 5;128(21):2856-60. doi 10.4103/0366-6999.168041. PMID:26521781; PMCID: PMC4756876.

31. Gross JB. Estimating allowable blood loss: corrected for dilution. Anesthesiology. 1983 58:277-280 doi: 10.1097/00000542-198303000-00016.

32. Conteduca F, Massai F, Iorio R, Zanzotto E, Luzon D, Ferretti A. Blood loss in computerassisted mobile bearing total knee arthroplasty. A comparison of computer-assisted surgery with a conventional technique. Int Orthop. 2009 Dec;33(6):1609-13. doi 10.1007/s00264-008-0651-7. Epub 2008 Sep 2. PMID: 18762940; PMCID PMC2899193

33. Vandenbussche E, Duranthon L, Couturier M, Pidhorz L, Augereau B. The effect of tourniquet use in total knee arthroplasty. Int Orthop.2002; 26(5):306-309.

34. Kajja I, Bimenya GS, Eindhoven B, Jan Ten Duis H, Sibinga CT. Blood loss and contributing factors in femoral fracture surgery. Afr Health Sci. 2010 Mar;10(1):18-25. PMID: 20811520; PMCID: PMC2895790.

35. Samama CM (2004) A direct antifibrinolytic agent in major orthopedic surgery. Orthopedics 27(6 Suppl): s675-s680

36. Repicci JA, Eberle RW. Minimally invasive surgical technique for unicondylar knee arthroplasty. J South Orthop Assoc. 1999; 8:20-27.

37. Tria AJ Jr, Coon TM. Minimal incision total knee arthroplasty: early experience. Clin Orthop Relat Res.2003;416:185-190.

38. Choi Y, Yang HS, Park SE, Kim DY, Kim HK. Tourniquet induced hypertension and vita sign changes in elderly patients associated with tourniquet use under general or epidural anesthesia for total knee arthroplasty. Korean J Anesthesiol. 1999; 36:653-659. 